\title{
Launching Effect of COVID-19 Macroeconomic Destruction as a Catalyst for Localization of Types of Financial Behavior of the Population
}

\author{
Razumovsky D.Y.* Yuzvovich L.I. \\ Ural State University of Economics, Ekaterinburg 620144, Russia \\ "Corresponding author. Email: jobs.mail35@gmail.com
}

\begin{abstract}
In this article, the authors have made an attempt to offer a model typology that allows you to rank households according to the propensity to make financial decisions and consumer preferences. The use of the proposed typology makes it possible to predict the financial behavior of the population in the event of destabilization of the macroeconomic environment caused by the outbreak of a new coronavirus infection COVID-19. The authors systematized the behavioral characteristics based on the analysis of modern models of financial behavior, and a number of studies of the psychological and economic characteristics of people and formed 11 typological portraits of people's financial behavior. It is shown that this typology is especially noticeable in the conditions of volatility of macroeconomic indicators, although the basis of the typology is psychological, emotional and other subjective personality traits.
\end{abstract}

Key words: financial behavior models, financial decisions, consumer preferences

\section{INTRODUCTION}

Changes inherent in all socio-economic processes are characterized by a high speed of dynamics regardless of the orientation. There are many factors that influence these changes, including the development of technology [8], geopolitical issues, and even the epidemiological situation in the world - as recent events show. The speed of spread, development within the human body and the consequences of the new coronavirus infection COVID-19 make it urgent to make changes at the state level, not only in the daily rhythm of life of the population, introducing restrictions on freedom of movement outside housing, but also in financial, economic and industrial clusters of state management through regulations aimed at minimizing the impact of epidemiological conditions. The ongoing changes make it necessary to adapt customary methods of public administration, business, and household. The volatility of consumer demand is to a large extent due to macroeconomic dynamics, along with consumer preferences [7], as proved by international research of G.F. Gossena, F. Edjuorota, D. Kanemana, A. Tversky, R. Thalera and many other scientists. The cyclical nature of the latter is especially acute in the Russian national economy, which is subject to the influence of external market conditions and, first of all, world prices for hydrocarbons [11].

\section{PROBLEM STATEMENT AND METHODS}

Deterioration of macroeconomic indicators affects all economic agents, but first of all - the households that have to adapt to the dynamic conditions as the main ones [1]. Such adaptation is realized in the necessity of making many financial decisions. The ability of people to make financial decisions is closely linked to the desire for rationality [3]. Making rational, and thus safe, decisions that do not threaten the financial situation should at the level of society protect households from credits, bankruptcy and poverty - threats that are consistently linked to each other.

The authors believe that the growth in the number of poor people is correlated with the increase in the debt burden of citizens, especially during periods of liquidating businesses, reducing the quantity and quality of jobs [2]. The mechanism of this process is as follows: if an individual or household has income insufficient for the desired level of consumption, the individual or household has to resort to consumer credit (credit cards, commodity, educational, medical, vacation, funeral and other loans). Obviously, in this case, those benefits that were financed from credit resources are more expensive for consumers (taking into account the cost of borrowing), and provided there is no income growth, the share of expenditures for the benefits consumed increases. Solving the problem at this stage, people make objectively irrational, but in specific situations - inevitable decisions on re-lending debt restructuring, which traditionally does not improve the situation of borrowers, because the credit burden increases the period of credit, that is, what is called "overpayment" becomes scattered in time. Since the majority of people - as the statistics shows - follow this very path, rather than looking for ways to increase their income, a vicious circle is formed: poverty reproduces and aggravates poverty, preserving and strengthening habitual consumption - buying basic foodstuffs, paying bills and purchasing necessary goods of the industrial group (household) [10]. In this case we are not talking about preferences as motivators of decision-making, we are not 
talking about consumer preferences, because there is no choice - a necessary condition for this; the choice becomes either extremely limited or completely absent. People stop making decisions in the sense that preliminary planning and choice of several similar alternatives is really implemented [4]. Financial constraints make it impossible to plan and choose on the basis of desire; people have to base their choice on an affordable set of products rather than on preferences in the traditional sense. Moreover, there is a narrowing of opportunities to increase income, a key parameter in making financial decisions based on consumer choice.

\section{RESEARCH RESULTS}

If manifestations of macroeconomic instability objectively worsen the situation, the simultaneous decline in income and rising prices provoke a forced type of behavior based on making financial decisions with no choice, so such decisions form negative consequences - credit and poverty and exacerbate them. From the research point of view, it is of interest to analyze such distorted and forced types of financial behavior patterns in order to understand general trends of financial decisions made by people for the purpose of their subsequent prevention. What kind of prevention do the authors mean? - First of all, it is financial education and enlightenment, which will allow people to refuse, for example, to participate in financial pyramids in the hope of fast passive income, but leading, as we know, to the loss of those savings, which are often the last. In addition, measures to educate the public about the rights of consumers of financial services, which makes them protected from the bad faith of some financial intermediaries and a number of others, are preventive.

In considering models of financial behavior, the authors rely on a set of stable psychological and economic qualities of people (or groups of people united by common life - households), which conditioned the skills of receiving and disposing of money. The said set may be determined or changed under the influence of objective and subjective factors to different degrees. Financial behaviour, in the opinion of the authors, consists of making decisions in respect:

1) purchase of necessary goods;

2) financing autonomous costs and liabilities;

3) savings formation;

4) searching for instruments and directions of investment placement;

5) providing insurance coverage;

6) search for sources of fundraising (loans, etc.);

7) buying other goods;

8) financing entertainment.

The hierarchy according to which the necessity of making the listed decisions arises is approximately the same as it is presented - from necessary purchases to entertainment, even at different levels of income people find different opportunities to satisfy their basic needs, then moving to excesses. It does not happen otherwise: people with low income do not seek to buy expensive food, while refusing the following hierarchy positions available to them [9].

On the basis of the analysis of many results of researches conducted both in the world and in Russia, the authors proposed 11 types of financial behavior of people, which they demonstrate in conditions of an unstable macroeconomic situation (Figure 1).

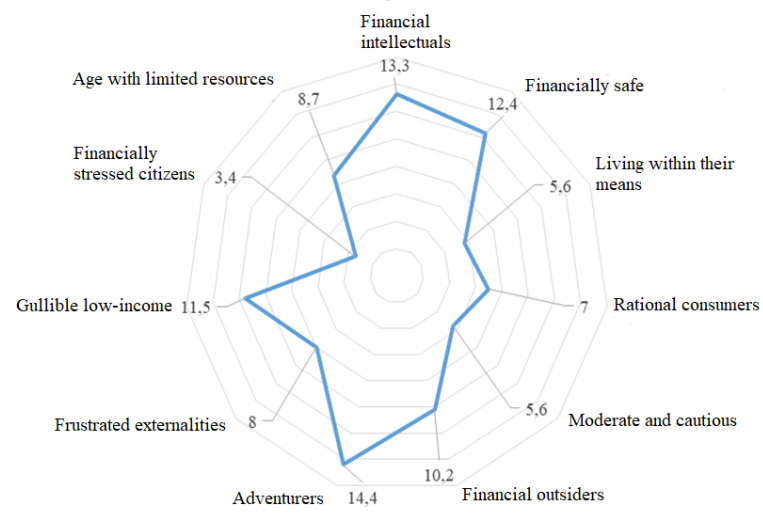

Figure 1: Model typology of financial behavior of the population

Each of these types of financial behavior can be interpreted on the basis of its inherent typological characteristics, which, in turn, make it possible to forecast the range of financial decisions that are likely to be made by representatives of the respective types.

The listed types of financial behavior are determined not only by external macroeconomic conditions but also by subjective personality traits, aptitudes, habits, and abilities, among which the authors have identified the most significant ones:

- adventurism and an increased propensity for financial risk, gambling;

- financial responsibility (locus of control);

- $\quad$ laziness, unjustifiable minimization of effort and time to make decisions;

- $\quad$ propensity to make a decision under the influence of the opinion of a reference group, exposure to information cascades;

- $\quad$ tendency to be adventurous, to engage in dubious operations;

- diffuse trust;

- paternalism.

\section{DISCUSSION}

According to the authors, the spread of the new coronavirus infection COVID-19 is a dualistic event from an economic point of view. On the one hand, the virtually uncontrollable rate of spread of the disease causes the government authorities to freeze the functioning of virtually all spheres of activity of organizations, causing serious economic damage with a long recovery period. However, on the other hand, the nature of shocks, caused by narrow and complex specifics for studying and 
understanding, weak possibility to predict its development and feeling of insecurity for all strata of population, catalyzes the need for self-preservation in a person by accumulating all available means for further existence and the subsequent structural analysis of distribution in directions with the maximum period of spending, thus optimizing own available financial resources.

Figure 2 shows the GDP dynamics of groups of countries ranked by the level of industrial and economic capacity development.

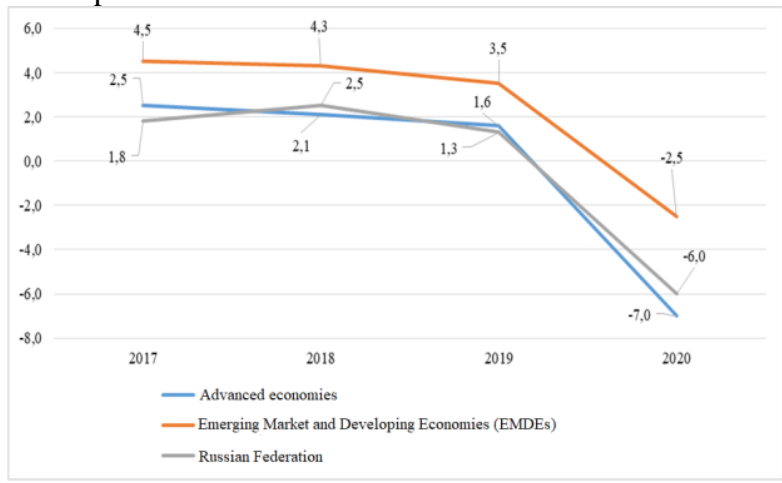

Figure 2: GDP dynamics of groups of countries ranked by level of industrial and economic capacity development

\section{CONCLUSION}

Rapid global GDP decline in 2020 is due solely to the scintillation of COVID-19 infection, the main way to prevent and minimize morbidity worldwide has been the introduction of a self-isolation regime with the shutdown of most organizations. The global trend of morbidity and further consequences of infection among all segments of the population contributed to minimizing consumer activity. However, it should be noted that in the period of declining rates of morbidity, one of the ways to activate economic activity on the macro level on the part of the state was an additional reduction in the key rate of the Central Bank of Russia. The cheapening of credit products for the population is also dualistic: July 2020 was a record year for Russian banks in terms of both the volume of mortgage loans issued and the interest rate. Sales figures allow us to conclude that we should expect further volume growth closer to the end of the state support program, and in case of its collapse - a sharp decline.

It was preferential mortgage programs that became the driver of economic growth in July. According to the United Credit Bureau, 129,000 mortgage loans worth 320 billion rubles were issued, which broke all previous records. But record-breaking was not only the volume of mortgage loans but also the interest rate on them.

It should be noted that the risks of epidemiological threat, the gradually exhausted financial resources of households, and the measures taken by the state authorities to activate the economy together will produce escalated financial and psychological characteristics in society. Types of financial behavior give grounds for ranking them at the first stage by the degree of people's exposure to potential risk, in making financial decisions. In the second stage, according to the set hypothesis, the authors have singled out population categories according to the criterion of exposure to changes in macroeconomic conditions. The importance of creating such categoricality lies in the ability to predict behavioral trends in the event of unfavorable market changes - price and devaluation shocks, the dominance of panic moods in financial markets and others, which, superimposed on the individual personality, are able to provoke massive consumer and speculative waves. Recognizing that the presented functional structure of financial behavior is a unified simplification of reality, the authors consider it suitable for further economic and mathematical modeling.

\section{REFERENCES}

[1] Official website of the analytical center NAFI, https://nafi.ru/

[2] Official website of the FSGS RF, https://gks.ru

[3] Official site of the Central Bank of the Russian Federation,

https://www.cbr.ru/Ankets/MailForm.aspx?PartID=fing ram.

[4] E.A. Razumovskaya, Personal financial planning: theory and process modeling, Deutschland,

Saarbrucken: Palmarium Academic Publishing, 2016.

[5] E.A. Razumovskaya, D.Yu. Razumovskiy, Approaches to assessing the optimality of the structure of household financial resources and financial literacy of the population6 Finance 1 (2020) 57 - 64.

[6] R. Thaler, New Behavioral Economics: Why People Break the Rules of Traditional Economics. - M .: Publishing house "E", 2017.

[7] D. Brounen, K.G. Koedijk, A.J. Rachel, Household financial planning and savings behaviour, J. of International Money and Finance 69 (2016) 95 - 107. DOI:10.1016/j.jimonfin.2016.06.011

[8] M. Burke, J. Fry, How easy is it to understand consumer finance? Economics Letters 177 (2019) 1-4. DOI:10.1016/j.econlet.2019.01.004

[9] A. Cardaci, Inequality, household debt and financial instability: An agent-based, Journal of Economic Behavior \& Organization 149 (2018) 434 - 458. DOI:10.1016/j.jebo.2018.01.010 
[10] D. French, S. Vigne, The causes and consequences of household financial strain: a systematic review, International Review of Financial Analysis 62 (2019) 150 - 156. https://doi.org/10.1016/j.irfa.2018.09.008.

[11] P.K. Ozili, Impact of digital finance on financial inclusion and stability, Borsa Istanbul Review 18(4), (2018) $329-340$. 